\section{ISSN 1991- 8690}

website :http:// jsci.utq.edu.iq

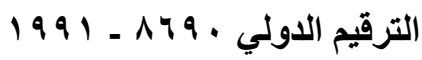

Email: utjsci@utq.edu.iq

\title{
Relationship of Soft X-Ray caused from Solar Flares and Solar Energetic Particles at Maximum of Solar cycle 24
}

\author{
Habeeb. H.Allawi
}

Department of physics _ college of Science . Thi Qar University

\begin{abstract}
$\underline{\text { Abstract }}$
In the current research we studied solar flares and their associated interactions of solar energetic particles (SEPs) and productive relationship with X-rays generated in these blasts. Goal of this study is to detect the correlation between soft X-rays associated with SEPs. We take into consideration rely on soft X-ray emission associated with these particles as a reference guide to keep track of these particles. In this study we used three satellites research, a satellite (ERNE) which used to detect the intensity of solar energetic particles, and this satellite belonging to the U.S. space agency (NASA) in collaboration with the European Space Agency (ESA). The satellite research (GOES) to observe the solar Xrays flare, as well as satellite research (WIND WAVE) which has been used to detect solar radiation emissions, in addition to the data we have obtained from the International Space Station (SOHO). The study was conducted for a full year (2012) at the maximum active of the solar cycle (24), where the analysis of all the data that have been obtained. The main objective of the research is to investigate the direct link between the solar soft X-ray and non- thermal solar particles reaching the ground. The study found that the soft X-rays class $\mathrm{X}$ resulting from solar flare be associated with solar particle stimulant SEPs generated and to the fact that radiation generated by a class $\mathrm{X}$ is composed at the same time in which it occurs explosions of coronal mass ejections CMEs. The study also showed that the time for the emission of solar particles stimulant happens after a few minutes after the arrival of X-ray generated to the top of eruption.
\end{abstract}

Key words: solar flare, coronal mass ejection, solar energetic particles.

العلاقة بين الاثعة السينية الخفيفة الناتجة من الشعيلات الشمسية و الجسيمات الثمسية المنشطة عند قمة الدورة

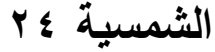

$$
\begin{aligned}
& \text { حبيب حرز علاوي } \\
& \text { قسم الفيزياء ــ كلية العلوم - جا معة ذب قار }
\end{aligned}
$$

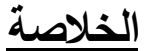

في البحث الحالي تمت دراسة الانفجارات الثمسية ومايصاحبها من تفاعلات منتجة للجسيمات وعلاقتها بالاشعة السينية المتولدة في هذه الانفجارات.الهدف الاساس من هذه الدراسة هو الكثف عن صلة التزابط بين الاشعة السينية المنولدة والجسيمات الثمسية المنبعثة نظرا لأهمية الجسيمات

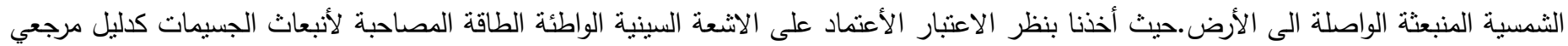
التتبع هذه الجسيمات.اعتمد في هذه الدراسة للحصول على البيانات العملية علميا على ثلاث اقمار صناعية بحثية وهي القمر الصناعي ايرني (ERNE) والمستخدم لقياس فيض الجسيمات الثمسية المنشطة وهو قدر تابع لوكالة الفضاء الامريكية ناسا (NASA) بالتعاون مع وكالة الفضاء الاوربية ايسا

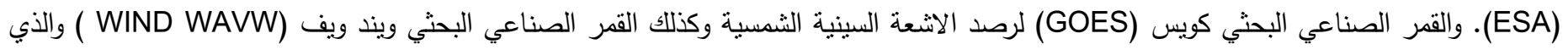

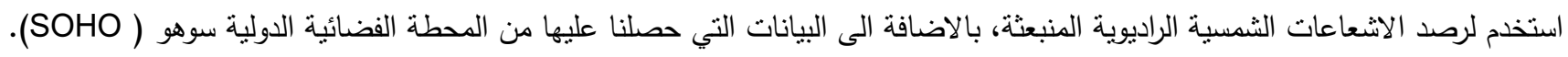

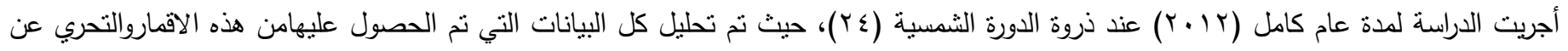

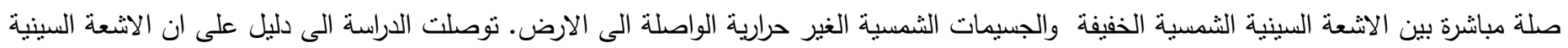
X المنولدة من فئة 


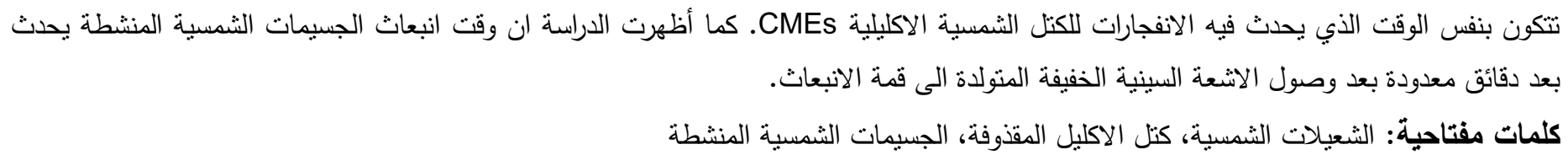

\section{Introduction:}

Solar energetic particle (SEP) events are an important element of solar-terrestrial relations and space weather. Significant efforts are devoted to develop the understanding of their relationship with soft $\mathrm{X}$-rays caused from flares and (halo) coronal mass ejections (CMEs).This based on empirical correlations of SEP peak flux with soft x-ray parameters, despite the fact that there need not be a direct link between the thermal soft $\mathrm{X}$-rays and non-thermal energetic particles.An important aspect is determination of the acceleration and injection Profiles of solar energetic particles (SEPs) at the sun. Solar energetic particles produce from eruptions come from flares (Impulsive) or coronal mass ejection (CME) (gradual). Same time we could recognize this eruption by look at the properties of SEPs, radio emissions, seeds, and $\mathrm{X}$ - ray duration time. SEPs are believed to be accelerated in the lift-off phase of CMEs, which could include either acceleration in flaring processes (de Jager, 1986)[1], acceleration in coronal/interplanetary shocks (Reames,1999)[2], or in both (e.g Klein And Trottet,2001; Kocharov and Torsti 2002) [3,4].The solar flare is characterized by a sudden increase in electromagnetic radiation, as a result of heating and particle acceleration, which are thought to result from magnetic reconnection. Coronal mass ejections (CMEs) are large-scale structures carrying plasma and magnetic field from the Sun. The parameters of a CME should correlate with parameters of the associated flare that has been established by (Vrsnak et al. 2005)[5]. As the results of (Reames2009) [2] show, the release of SEPs near the Sun occurs within a few solar radii, Parameters of the shocks at such distances should be mainly determined by their initial sources and therefore related to the parameters of the associated flares. Also (Kahler,1994)[6] suggested that SEPs are typically released no earlier than the maxima of the flare impulsive phases. Radio emission is one of good method to trace shock waves. the frequency of radio emission depends upon the local electron density which decreases with distance from the Sun. Radio observations distinguished fast-frequency-drift type III bursts, produced by a burst of $10-100 \mathrm{keV}$ electrons frequency drift of type II bursts, traveling outward at speeds that corresponded to slower, around $1000 \mathrm{~km} \mathrm{~s}$ 1shock waves. Also he suggested that:

(1) electrons were accelerated to produce the type III bursts

(2) Protons were accelerated at shock waves seen as type II bursts.

Tousey (1973)[7] was the first observed CMEs, (Sheeley et al.,1975)[8] associated CMEs with long duration X-ray events(LDEs). (Kahler et al.1978)[9] were the first to show that all SEP events during the Skylab period were associated with a CME or an LDE. A stronger link to SEP events was established with the (Solwind) coronagraph data when ( Kahler et al.1984)[10] found a 96\% correlation between large SEP events and fast, wide CMEs. The important evidence that CMEs drive the shock waves that produce coronal(metric) type II bursts was presented by (Cliver, Webb, and Howard 1999) and is clearly established (Liu et al. 2009; Bain et al. 2012) [12,13].

\section{Methods and Calculations:}

In this present work, we studied selective six events of soft x-ray flare out of 2037 events happened at 2012 by using remote-sensing data observed by the (Geosynchronous Operational Environmental Satellite) GOES[14] with white-light data from the Large Angle Spectroscopic Coronagraph (LASCO: Brueckner et al.,1995)[15]. on the Solar and Heliospheric Observatory (SOHO). First check of CME in the Large Angle and Spectrometric Coronagraph (LASCO ), which are a strongest association events with 69 events of a halo CMEs in maximum of solar cycle 24 (cdaw.gsfc.nasa.gov/CME list/, Yashiro et al., 2004)[16] and by using the spatial and temporal proximities, it is possible to determine whether the flare is associated with a CME. We examined SEPs injection time by using the energetic and relativistic nuclei and electron (ERNE) instrument[17], Table (1) show in column 1and 2 number of events and date, column 3 and 4 a time of first view to halo CME in universal time (UT) and speed of coronal mass ejection . column 4,5 , and 6 represented a flare at time of maximum peak of Soft X-ray flux, location, and rank of this flux. Column 7 and 8 Injection time and energy of SEPS. 
Also we determine whether the flare is associated with a CME, which involves ranking the outflow or the lack thereof in coronagraph data. Finally, observed a radio emissions produced from shock waves of CMEs, by using WIND/WAVE spacecraft [18 ], to see DH type II bursts, and by using RAD1 base observatory [19] to observed metric type II bursts. Table( 2) shows a time, range frequencies and ranks of associated radio emissions with events of this study. Figure 2 shows radio emission type II bursts when its rises time is very near of injection time of SEPs. We used this method of tracing radio emissions to give right follow of shock wave from eruptions to the detectors.

Table (1) coronal mass ejections (CMEs) observed by the solar and heliospheric observatory (SOHO) mission, soft $\mathrm{X}$-ray flare size (peak flux in the 1-8 A channel) from GOES, and SEPs from ERNE

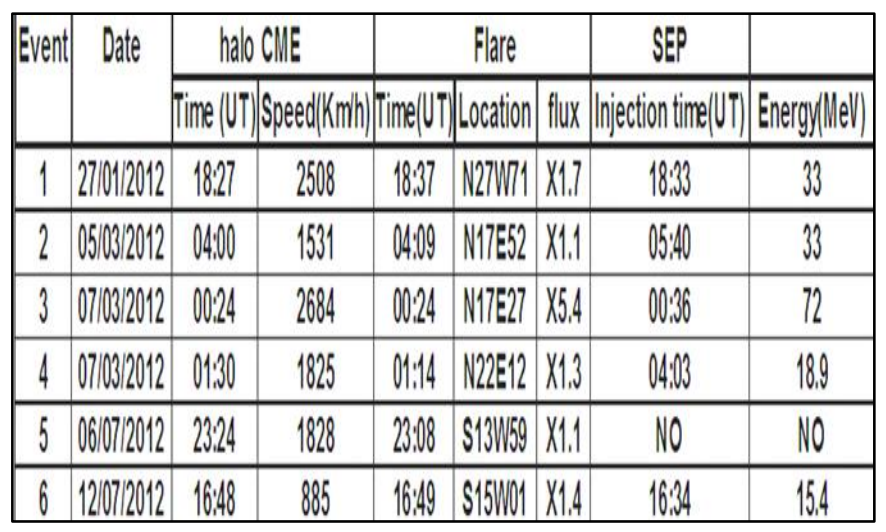

table (2) possible type ii and iv radio bursts observed by wind/waves and stereo/waves in 2012

\begin{tabular}{|c|c|c|c|c|c|c|}
\hline \multirow{2}{*}{$\begin{array}{c}\text { No. } \\
1\end{array}$} & \multicolumn{2}{|c|}{ Start time (UT) } & \multicolumn{2}{|c|}{ Stop Time (UT) } & \multirow{2}{*}{$\begin{array}{l}\begin{array}{l}\text { Frequencyl } \\
\text { Khz) }\end{array} \\
16000-150\end{array}$} & \multirow{2}{*}{$\begin{array}{r}\text { Type } \\
\|\end{array}$} \\
\hline & & 1830 & & 0445 & & \\
\hline 1 & 20120127 & 1845 & 20120127 & 2020 & $16000-10000$ & VI \\
\hline 2 & 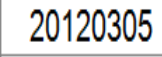 & 0400 & 05 & 1220 & & 11 \\
\hline 2 & & 0415 & & 0700 & & VI \\
\hline 3 & 07 & 0100 & 308 & 1900 & & $\|$ \\
\hline 4 & & 2310 & 7 & 034 & $16000-300$ & \\
\hline 5 & 20120712 & 1645 & 20120713 & 0900 & $14000-250$ & \\
\hline
\end{tabular}
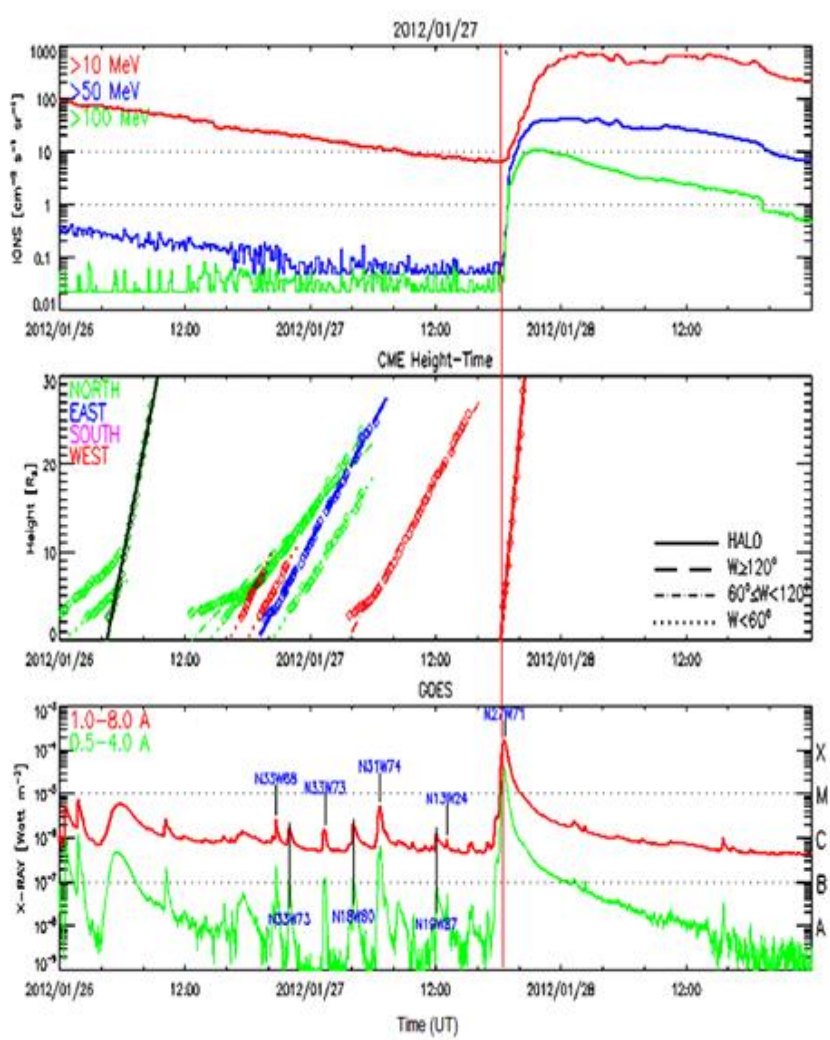

Figure 1 (proton, height-time, X-ray) link to three-day overview plots of solar energetic particle events (protons in the $>10,>50$ and $>100 \mathrm{MeV}$ GOES

\section{Results and discussion:}

Existing methods to diagnose SEPs productivity of a solar eruption, which just occurred, are not yet clear, and still high uncertainties exist in forecasting SEP events. That needs to know methods for better understanding of particle acceleration, when and where it occurs, and in which conditions. (Wild Smerd, and Weiss, 1963)[20] Suggested evidence of an alternative view of the nature of particle acceleration by observes a radio emission. The solar longitude distribution of large SEP events was studied by (Cane, Reames, and von Rosenvinge,1988)[21]. (Yashiro et al. 2005)[21], who carefully made associated CME-flare pairs during (1996-2001), the location-averaged CME association rate is roughly $20 \%, 50 \%$ and $90 \%$ for C-class, M-class, and X-class flares, respectively. When the two phenomena are associated, they tend to be closely related both temporally (Temmer et al., 2010)[22] and spatially (e.g. Yashiro et al., 2008)[23]. A main reason for reassessing the CME width is that many of the SEP events are associated with what are reported as "halo" CMEs in the catalog with angular width of 3600, ( 
Cane, et, al. 2010) [24]. This study give evidence that all events have strong soft $\mathrm{X}$-ray with rank X, same time associated with halo CMEs give us gradual of SEPs intensity time profile.(Figure 1), shows with very clear all onset time of events are matching with a scenario of producing SEPs.We could recognize that injection time of SEPs occurred after few minutes of lift off time of CMEs, these clues are matching excellent with previous studies. My results are in good agreement with past studies in confirming the importance of the flare parameters heliographic (longitude, peak intensity and duration) as indicators of the capability of a flare to produce a SEP event. Also I emphasis that CME shock continues to accelerate particles during its transit from the sun to the earth.

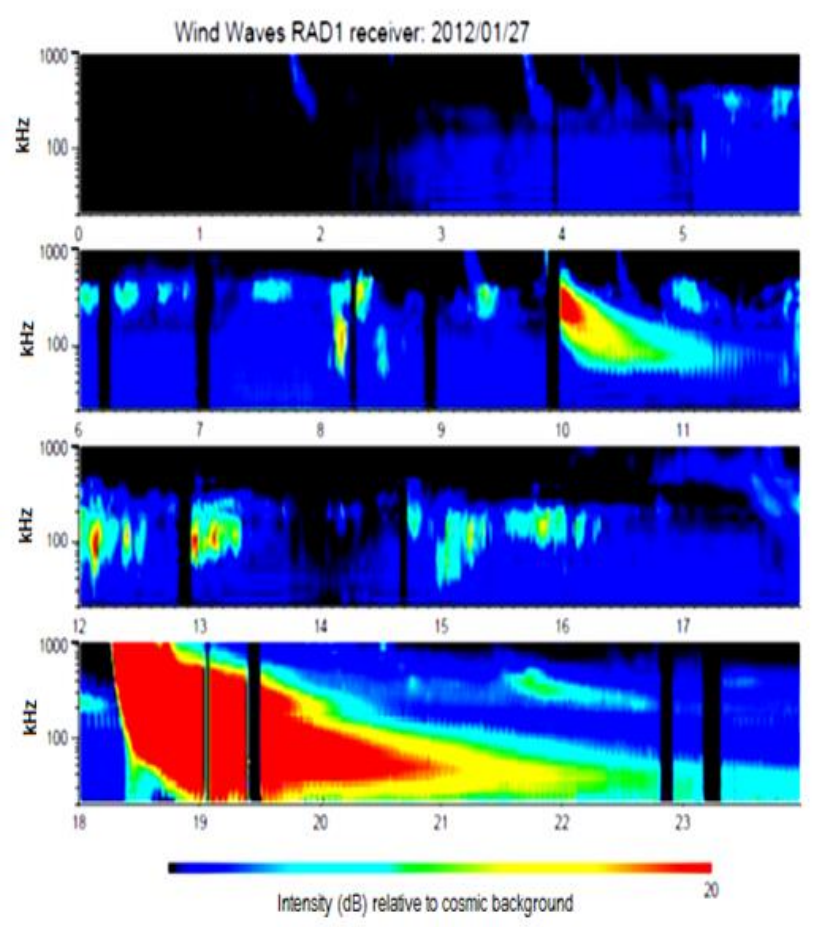

figure2 radio emissions burst of type ii to the event 27/01/2012 by wind/wave spacecraft

\section{References}

1. de Jager, C.,1986, Space Sci. Rev. 44, 43.

2. Reames, D.V, 1999,Space Sci. Rev. 90, 413.

3. Klein, K.-L. , , Trottet, G.: 2001, Space Sci. Rev. 95, 215.

4. Kocharov, L., Torsti, J. 2002, Solar Phys. 207, 149,

5. Vršnak, B., Sudar, D,\& Ruždjak, D, 2005, A\&A, 435, 1149.

6. Kahler, S: 1994, Astrophys. J. 428, 837.
7. Tousey, R.:Space ResearchXIIIed. Rycroft, M. J., Runcorn S.K.,1973, (Berlin:Academie-Verlag) p. 173.

8. Sheeley, N. R, Jr. et al. , 1975, Solar Phys. 45, 377.

9. Kahler, S. W., Hildner, E., and van Hollebeke, M. A. I.1978.: Sol. Phys. 57, 429

10.Kahler, S. W., Sheeley, N. R., Jr., Howard, R. A., Koomen, .J., .Michels, D. J., McGuire R. E., von Rosenvinge, T. T., and Reames, D. V. ,1984, J. Geophys. Res. 89, 9683.

11. Cliver, E. W., Webb, D. F., and Howard, R. A.: 1999, Sol. Phys., 187, 89,.

12 . Liu, Y., Luhmann, J. G., Bale, S. D., and Lin, R. P.,2009A, strophys. J. 691, L151.

13. Bain, H. M., Krucker, S., Glesener, L. and Lin, R. P. 2012: Astrophys. J. 750,44.

14. Donelly B.R., and Unzicker A. , 1974, NOAA Tech. Memo. ELR SEL-72.

15. Brueckner, G.E., Howard, R.A., Koomen, M.J., Korendyke,C.MMichels D.J., Moses, J.D., Socker, D.G, \& Linker, J, 1995, The Large Angle Spectroscopic Coronagraph (LASCO) Sol. Phys., $162,357$.

16. Yashiro, S., Gopalswamy, N., Akiyama, S., Michalek, G., Howard, R.A, 2005, JGR, 110, A12S05. 10.1029.

17. Torsti J., Valtonen E., Lumme M., Peltonen M. P., Eronen T., Lohola M.,Riohonen E., Schultz G., Teittinen M., Ahola K., Holmund C. Helha V., Leppala K., Ruuska P. and Strommer E., 1995,Solar Physics, 162 ;595-531.

18. Bougeret, J.-L., M. L. Kaiser, P.J. Kellogg, et al., "WAVES: The Radio and plasma wave investigation on the WIND Spacecraft"1995, Space Sci Rev, 71, 5.

19. NASA/NOWA. last update 2013

ftp://stereowaves.gsfc.nasa.gov/wind_rad1/rad1pdf/

20. Wild, J.P., Smerd, S. F., and Weiss, A. A. 1963, Ann. Rev. Astron.

21. Cane, H. V., Reames, D. V., and von Rosenvinge, T. T. ,1988, JGR. 93, 9555.

22. Temmer, M., Veronig, A.M., Kontar, E.P., Krucker, S., Vr`snak ,2010,Astrophys. J. 712, 1410 doi: 10.1088/0004-637X/712/2/1410.

23. Yashiro, S., Michalek, G., Akiyama, S., Gopalswamy, N., \& Howard, R. 2008 A.ApJ, 673, 1174,.

24. H. V. Cane, I. G. Richardson, and T. T. von Rosenving, 2010JGR, 115,A08010. 